and although the patient survired more than a fortnight, his state was such that no further operations were deemed expedient. The fourth patient was known to be suffering from chronic nephritis, but as the stone was small, and the operation speedily completed, there was every reason to hope that the renal complication would not become seriously aggravated. For forty-eight hours all went on well, but symptoms of uræemia supervened, and the condition soon became hopeless. The nine successful cases illustrate in various ways the advantages of Dr. Bigelow's method, the relief afforded in the majority of these instances being rapid and complete. Cases $1,2,5,6$, 7,9 , and 11 are particularly noticeable in this latter respect. In Cases 8 and 10 the accidents which occurred to the lithotrites complicated the proceedings and caused some delay in completing the operations. In the latter of these cases the stone was a very large one (40z. $140 \mathrm{grs}$ ), indeed it would appear to be the largest hitherto removed by lithotrity. In a case mentioned in Dr. Bigelow's work the fragments weighed $4 \mathrm{oz} .52$ grains, and the removal required three sittings occupying eight hours and a quarter. In the present case, in spite of the delays caused by the giving way of the instrument, the operation was completed in three hours and a quarter. The successful result in both of these cases justifies the belief that calculi four ounces in weight may be dealt with by Bigelow's operation provided that the condition of the bladder is favourable to lithotrity, and that instruments can be constructed capable of bearing the enormous strain involved in crushing. On examining Bigelow's lithotrite one is struck by the enormous power of the blades as contrasted with the imperfect manner in which the handle is connected with the shaft and the consequent inadequate resistance to the force applied by the screw. This imperfection, however, can doubtless be remedied. Care has been taken to point it out to the makers of the instrument. The remaining mechanical portions of Bigelow's instrument leave little to be desired. The ball by which the screw-power is applied, and the revolving cylinder-handle for opening and closing the lock, are decided improvements upon the wheel and button of former instruments when large stones have to be dealt with, while the power of the blades has been sufficiently tested in the cases just referred to. With regard to the time occupied in the operation, Dr. Keyes states that he removed from nineteen patients 4241 grains of stone in 938 minutes, or on an average 41 grains of stone for each minute of work. The total weight of débris removed in the ten cases of this series was 3133 grains, the time occupied in the operations being 454 minutes. This gives an average of nearly seven grains per minute of work. With instruments improved as suggested it is probable that this average might be much increased.

Harley-street, W.

\section{AN OUTBREAK OF TRICHINOSIS (?) FROM EATING THE FLESH OF A WILD BOAR.}

BY JOHN WORTABET, M.D.

PHYSICIAY TO ST. JOHN'S HOSPITAL, BEYROUT.

TrE village of Khiam, where this disease has recently broken cut, lies not far from the principal sources of the Jordan, which, losing themselves in the plains of El-Huleh, form a large marsh. From the thick jungles of papyrus which occupy that marsh a large wild boar was shot and brought to Khiam on the 25th of November. This was a great treat to the poor villagers, who can rarely afford to indulge in butcher's-meat, and many of them ate the flesh, partly raw and partly half-cooked. The meat was observed at that time to be perfectly fresh and good, and no one noticed that it was in any way diseased; but during the course of the second week all the persons who had eaten became ill, and if any escaped at that date they suffered a short time later. Of those who had abstained not one fell ill. The nature and symptoms of the disease were the same in all the victims; but those who ate the flesh raw suffered most severely, and the children generally suffered less than adults. The head of the boar was sent as a present to a family in Hasbeya, some miles north of Khiam, who boiled it very thoronghly before cating it, and though a good number.

These facts I verified by visiting the place of the disaster, which is a two days' journey from Beyrout, and where I spent Jan. 1st and $2 n d$ in studying on the spot all the circum. stances of the case. I found 257 persons more or less illviz., men, 121 ; women, 101 ; children, 35. Five othersthree men and two women-had died before my arrival. I carefully examined the symptoms and the course of the disease in a large number of those cases, about which there was a remarkable and almost wearisome identity. The main points were as follows:-From ten to twenty days after eating of the meat the face and extremities became cedematous, the swelling extending over the whole body. This was accompanied by severe pain in all the muscles, with more or less fever. These phenomena did not generally continue more than two or three weeks, and were followed by a slow convalescence with much weakness and lingering muscular pains, and occasionally by slight relapses. I shal now proceed to state the matter in a somewhat more de. tailed manner.

As I entered the village I was at once surrounded by some twenty men, women, and children, all of whom had been among the victims. Their faces were still puffy and pale and they looked very weak, but convalescent. They al had one story to tell : "We ate of the flesh, but did not feel unwell till some days after, when we had much pain all over the body, swelling, and fever. We are now much better, but very weak, and not free from pain yet." In examining carefully a few of the cases I found nothing more than they had stated. The tongue was clean, the appetite good, and the functions of the alimentary caual normal. In almost every case, however, there was a peculiar appearance of the floor of the mouth, the inferior surface of the tongue, and the gums. Situated on the mucous membrane there were small white conical projections, a few of which I clipped and subsequently examined with the microscope, but with nega tive results as to the existence of any parasite within them The gum often presented the appearance of congested patches, while at its border, where it dips into the alreoli, it was sometimes red, and bled easily on pressure.

The period of incubation does not seem to have ever been under ten days, though it was prolonged in some cases to twenty. In one individual, who had eaten the meat fairly cooked, the disease did not appear before the end of the fourth week, and then it was so slight that he was not laid up by it. I asked particularly whether they, or any of them, felt unwell during that time, and they were all unanimous in saying that up to the date of the actual invasion of the disease they felt as well as usual. I heard, however, of one man who had vomiting and diarrhœe soon after eating, probably the effect of an overloaded stomach, and that he was one of those who had suffered the least. The instances in which the disease appeared later than the second week were very few.

The order of the symptoms, after the disease was fully declared, appears to have been, as far as I could find out, a swelling of the face and extremities, accompanied or soon followed by severe pain in all the muscles of the body, and more or less fever, with headache, thirst, perspiration, and much itching of the skin. These symptoms continued about two weeks, and it was during this period that five persons died, apparently from the effects of the fever. The majority of the sick became then slowly convalescent and left their beds. Having learned this much from these people I next visited the sick who were still confined to their beds. This number could not have been far from 100, but most of them were evidently beginning to recover, and with the ex. ception of an redematous state of the face and extremities, and lingering pains in the muscles, with, perhaps, a slight febrile reaction towards the evening, there was nothing particular to observe. The severer cases, which were no more than five or six, presented still the typical features of the disease. The fever was of an asthenic form, in one case with a dry typhoid-looking tongue, and appeared to be of a secondary ebaracter in the chain of morbid phenomena, and probably produced by a general irritation of the whole system. The pain, which seemed to invade all the viluntary muscles, was very severe, but appeared most in the muscle of the extremities and at the different points of their attachments to the bones. Both flexion and extension were rery painful, and the patient lay generally on his back, with lifs limbs in a state of semi-flexion. In one instance I foumd the calf of the leg hard and very tonder on pressure. EFery 
movement gave pain, and the muscles of mastication, swallowing, and breathing seemed to be all equally implicated. The roice was somewhat husky, and there was pain in the region of the larynx. At one time during the march of the disease they complained of a swelling in the tongue, and some had suffered from conjunctivitis, of which I saw two instances. The bowels seemed to have been regnlar throughout, and I was struck by the normal state of the alimentary canal and digestive functions where there was so much suf. fering and constitutional disturbance. some of those who were still sick in bed had been better, but had relapses, which they attributed to imprudence on leaving their room too soon.

I asked the older men of the village whether they had ever observed such a disease among them from eating the flesh of wild boars, which are frequently hunted during winter from the neighbouring jungles. They said they never had anything of the kind, but that some ten years ago there was a similar outbreak from the same cause in the village of Kiniat, a few miles to the east, and when about twenty persons lost their lives. I had a confirmation of this from other quarters, and I have no doubt that it was true. I was told, also, that the wild boar lives chiefly on the roots of the canes which are so abundant in the marshes, and as he burrows the ground with his snout he snaps up small animals, such as worms, snakes, and wild rats-the latter of which are said, I believe, to be sometimes infested with the trichina spiralis.

Was this outbreak, then, in Khiam one of trichinosis? I am sorry to say that the one incontestable proof-the microscopic demonstration of the parasite-is up to this date still wanting. No case of death took place while I was there, and to open a grdve would have been perhaps impossible. All traces of the boar had disappeared. One brave man offered his arm for examination, but I did not like to inflict pain and injury on the poor fellow who was still suffering severely from the disease. I heard of a cat which had eaten of the meat and died, but it could not be found. I heard of another in regard to which the statements were very contradictory as to whether it bad eaten or not. It appeared well and quite lively. On killing it, however, and examining different pieces of muscle with the microscope, I found them quite healthy and free from the parasite.

I still hope to obtain a piece of muscle for examination from one of the bodies of those who died from the disease, and to communicate the result. In the meantime it is quite rational to believe, judging from the history of the outbreak, and from the symptoms of the disease, that we had here probably another instance of a trichinatous infection on a larger scale than has hitherto been recorded. If it were not that, what else could it have been?

Suhsequently I received a letter from the pastor of the Protestant communiry in that village, in which he saya: "No more deaths after you left us. The patients are gradually improving, and those who are still in bed are few; but some are still swollen, and complain of pain in the hands and feet. They are all very weak and incapable of work, while a few have intermittent fevers, for which they are taking quinine."

P.S.-Since writing the above one of the victims mentioned-a some what aged woman-whom I had seen quite ill when I was there, has died, and I have succeeded in obtaining from the body a piece of muscle (biceps brachialis) which reveals under the microscope a good number of trichinæ, and sets at rest any question as to the nature of the disease. The parasite lies coiled across the primitive fibres, and apparently within the sarcolemma of the fdsciculi, and appears to be free-not enclosed in a cyst. 'The stage of calcification of the capsule may not have been reached, of the sac may have been too trausparent to allow of detection. The trichiua may be obtained free of the muscular tissue by a moderate pressure of the covering glass, but they are apt to get thus uncolled, and to lose their characteristic spiral forin. I have had a few specimens mounted, and will try to send a piece of the muscle itself hy this mail. To the naked eye the tissue has a perfectly healthy appearance. I have also received another letter from the village, which states that they were having a good number of relapses, and mentions particularly a return of the sweling, of muscular rain, chiefly at the bent of the elbows and knees, and of much itching over the whole body. The patients complain of a sense of sudden failing if they cannot get at food as soon as there is a craving for it. Many are still in $b=d$, and tho:e who are able to be out feel very weak, and continue to feel pain. I fear there will be some more fatal cases. Beyrout.

[NoTE.-We received from Dr. Wortabet a specimen of muscle referred to in the postscript, and on submitting it to microscopical examination, we found it to contain a large number of non-encysted embryo nematoids. An examination of the isolated worms showed them to possess the general shape, with terminal anus, met with in the embryos of trichina suiralis. They were too immature to admit of any details of organisation being made out. They were found to be $\frac{1}{30}$ " long by $\frac{1}{100} "$ broad. For the most part they were situated in the midst of small connective tissue overgrowths between the muscular fibres, and the fact that they were non-encysted is in accordance with the otber fact that they had not yet attained the usual size of encysted trichine.-ED. L.]

\section{ON THE}

\section{ANTIPYRETIC TREATMENT OF TYPHOID FEVER BY MEANS OF SODIUM SALICYLATE.}

BY HENRY TOMKINS, M.D.,

MEDICAL OFFICER TO THE MONSALl FEVER HOSPITAL, MANCHESTER. (Concluded from page 410.)

OF the total number of patients treated, 14 (6 male and 8 female) proved fatal, and at first sight this may not appear to present a very favourable case for the employment of the sulicylate. Forty-six cases show a mortality of 14, or something like 30 per cent., but the fallacy of mere figures is proverbial, and before hastily coming to an adverse conclusion several qualifying conditions are to be taken into account. Firstly, the whole of these are selected cases - selected on account of their marked severity, - those cases in which the ordinary resources of medicine and therapeutics offered at best but a faint hope of success ; they were, in fact, chiefly that 15 or 20 per cent. which up to the present all our efforts have been unavailing to save. Again, in addition to the well known fact that the cases brought for treatment to hospital are, as a rule, more severe than those treated elsewhere, there is this to be borne in mind, that during the time over which these extend the patients admitted here include a large proportion of pauper cases, the mortality among whom is always higher than in those of a better social status, as is well shown by the statistics of the London Fever Hospital, where, after the exclusion of pauper cases, the death-rate at once was considerably lowered. But further, on examining these 46 cases, it is found that 5 of them were almost hopeless on admission, and in 4 death was the result of intestinal hæmorrhage and lung complication.

A point deserving of some attention is that in a large proportion of the fatal cases the temperature resisted the antipyretic action of the soda, even when pusbed to extreme doses; and from my experience I would submit that whenever the poison apuears to bave got so firm a hold of the system that the salicylate in full doses, atter twelve' hours administratiou, has failed sensibly to reduce the temperature, the prognosis is most unfavourable, and its further use is not to be persisted in.

Would space permit, more complete details of the above would furvish abundaut proof of the power the sticylate has in rapidly reducing the pyrexia, and influencing beneficially the course of the disease, but one case only must here sutfice.

Sarah $\mathrm{H}-$, a fairly well-nounished child, aged seven, admitted April 9th, 1879 , with indistinct history of vomiting, headache, and purging; ailing about a week. Complains now only of lieadache and feeling tired. Face flinshed, much hebetude, intellect confused, rambling when left alone. Abdomen distended; pain and yurgling in iliac fossa. Area of spleuic dulness enlarged. Temperature on evening of admission $103^{\circ} \mathrm{F}$; pul-e 136 -April 10th: Text morning the temperature had fallen half a degree; pulse 128 ; respiration 30 . Lungs nnrmal; urine free from albumen; purged twice in the uight, "pea-soup" stools. Tongue 